\title{
Erratum: Emittance Preservation in an Aberration-Free Active Plasma Lens [Phys. Rev. Lett. 121, 194801 (2018)]
}

\author{
C. A. Lindstrøm, E. Adli, G. Boyle, R. Corsini, A. E. Dyson, W. Farabolini, S. M. Hooker, M. Meisel, \\ J. Osterhoff, J.-H. Röckemann, L. Schaper, and K. N. Sjobak
}

(Q) (Received 12 March 2019; published 29 March 2019)

DOI: 10.1103/PhysRevLett.122.129901

It was recently discovered that the calibration of the toroids used to measure beam charge in this experiment was wrong by exactly a factor 10; i.e., the charge values quoted in the Letter were 10 times smaller than the true values. This implies that the charge during transverse offset scans (Fig. 2) was 50-70 pC per bunch (instead of 5-7 pC), and the charge during emittance measurements (Fig. 3) was $20 \mathrm{pC}$ per bunch (instead of $2 \mathrm{pC}$ ).

This recalibration has no impact on the conclusions of the Letter since the charge in each measurement was adjusted specifically to avoid interference from plasma wakefields. However, the increased charge values are of interest as they imply emittance preservation for an order of magnitude more intense particle bunches.

Published by the American Physical Society under the terms of the Creative Commons Attribution 4.0 International license. Further distribution of this work must maintain attribution to the author(s) and the published articles title, journal citation, and DOI. 